\title{
Exploitation of expert system in identifying organizational ethics through controlling decision making process
}

\author{
Yanal Mahmoud Mohammad Kilani ${ }^{a^{*}}$ and Ehab Kamal Haikal ${ }^{\mathrm{a}}$
}

${ }^{a}$ Isra University, Jordan

\begin{tabular}{l}
\hline C H R O N I C L E \\
\hline Article history: \\
Received: October 24, 2019 \\
Received in revised format: No- \\
vember 282019 \\
Accepted: December 22, 2019 \\
Available online: \\
December 22, 2019 \\
\hline Keywords: \\
Expert systems \\
Artificial intelligence \\
Human intelligence \\
Values and ethics
\end{tabular}

A B S T R A C T

This paper examines how expert system may negatively or positively influence ethical based decision making process in an organization. Expert system ethical characteristics are chosen; including lack of human intelligence, lack of emotions, accidental bias and lack of values. Depending on quantitative approach; and through distributing a questionnaire on (132) GM, Deputy GM, project manager and officer, it appeared that expert systems' characteristics negatively influenced on the degree of ethics within the organizational setting. According to analysis, it appears that lack of values and human intelligence were among the characteristics that hinder the ethical stream adoption within an organization leading to ethics problems and malfunctioning on the decision making process. On the other hand, lack of emotions appeared to have good impact on the ethical efforts within an organization. Researchers recommended taking extra measures of surveillance in terms of ethics for individuals who are supposed to develop and monitor expert systems.

\section{Introduction}

Life is becoming more complicated, technology has invaded many areas in our lives, and it has built the ability to perform many human activities in the same level of humans even better. Due to that complexity; human factor became more involved into organizing human interactions than performing certain activities that can be accomplished through technology, and due to the human acceptance of technology invasion, there appeared many areas where technology is the master not the human; which includes education, medicine, manufacturing and business (Dirican, 2015). By taking a closer look at that nature of human interaction with technology; we can see that technology can appear as a valid alternative for the human factor in many areas. This has led to make technology as the main operator of many actions and activities and human became a supervisor on these activities. Turban et al. (2010) also supported the same idea arguing that one of the evidences regarding the eligibility of human-technology relationship is the acceptance that technology was welcomed with, in addition to that, technology is resilient and flexible enough that human managed to design it and program it in a way that guarantees the best results. In thinking of how technology has taken over the human activities, one may think of manufacturing (machine), education (virtual lasses) and medicine (operative tools), but to think of technology taking over one of the most complex human activities (decision making) might be seen a little extravagant idea. How can a machine or any kind of technology program replace human factor in taking sensitive decisions! (Ransbotham et al., 2017; Kwakye et al., 2018).

\subsection{Problem Statement}

The idea of ethics in business has been the focus of scholarly contribution since early 90s; many authors have focused their attention on the existence of ethics in business environment and how it can contribute to the performance and wellbeing of

* Corresponding author.

E-mail address: yanal.alkilani@iu.edu.jo (Y. M. M. Kilani)

(C) 2020 by the authors; licensee Growing Science, Canada doi: $10.5267 /$ j.msl.2019.12.026 
the organization. They have connected ethics to many aspects of organizational operation including employee satisfaction, performance, work environment, leadership status and management. As early as 1987 Wigan came to argue that the ongoing developments of technology and the possibility of replacing humans with machines may contribute into creating problems within ethical behavior given that many activities will be accomplished using machine and the credibility of human race will be lost. The same idea appeared all over again with more development that came into existence in the 90s; Raho et al. (1994) supported the allegations by Wigan (1987) and argued that many organizational activities are now being endangered in taking an unethical stream due to the high dependency on technology and machine-operated activities. Khalil (1994) also agreed with the same idea stating that many activities that are operated now by machines require a high level of logic and ethics, the technological logic as not enough in that case and there is a need for the human logic or else, an opportunity for ethical malfunction will appear soon. Dillard and Yuthas (2001) argued that many ethical issues must be taken into consideration when depending on expert systems for decision making process. Authors added that the lack of human logic may contribute in decreasing the level of ethics in these systems leading to weak and fragile decisions which will end up harming the organizational setting. On the same track Hashem (2013) focused in his study on the advantages of expert system for the organization in fields of speed and advancement; however Hashem (2013) insisted on the fact that there is no certain system that can be valid enough to substitute human knowledge and expert and that can be suitable for all situations especially in fields of ethics and values which are known to be a part of the human nature and cannot be embedded within any program or software. On the other hand, a recent study by Leikas et al. (2019) claimed that human ethics and values can be embedded within expert systems through focusing on deploying them in the design and since these systems accepts data entry then it would be possible for such systems to digest and understand human ethics and work in accordance to them in a way that guarantees and ethical approach in its processes and conclusions. Based on the above argument, the current study examined the reality to expert systems exploitation in organizational setting in reference to its ability to control decision making process in accordance with ethical orientation within an organization. A set of ethical stance motivators were adopted in current study, it included (Lack of human intelligence, Accidental bias, Lack of emotions and Lack of values). The following model was developed based on the adoption of variables:

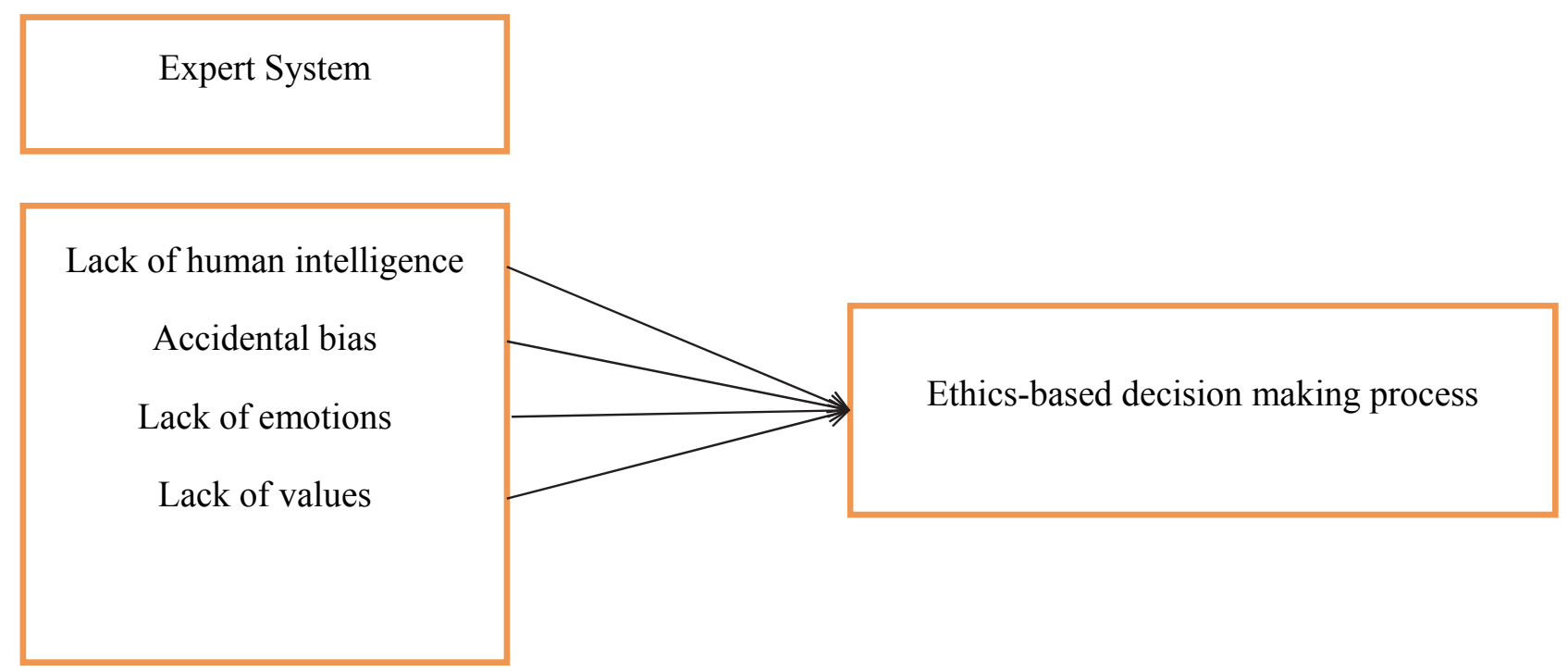

Fig. 1. Study Model

From the above model researchers were able to formulate the following set of hypotheses:

\section{Main hypothesis:}

Characteristics of expert system can influence ethics-based decision making process.

\section{Sub-Hypotheses:}

$\mathbf{H}_{1}$ : Lack of human intelligence can influence ethics-based decision making process.

$\mathbf{H}_{2}$ : Accidental bias can influence ethics-based decision making process.

$\mathbf{H}_{3}$ : Lack of emotions can influence ethics-based decision making process.

$\mathbf{H}_{4}$ : Lack of values can influence ethics-based decision making process.

\subsection{Scholarly Literature}

\subsubsection{Artificial Intelligence (AI)}

Algorithms and AI agents (or "artificial intelligence") affect many aspects of life such as: reading news articles, getting credit, and investing capital, among others. Because of their efficiency and speed, algorithms make decisions and implement actions 
on behalf of humans in these and many other areas. Despite these gains, there are concerns about the rapid mechanization of jobs, even cognitive functions such as journalism and radiology (Wu et al., 2014). According to Skilton and Hovsepian (2017) artificial intelligence is the ability of the machine to simulate the human mind and the way it works, such as its ability to think, discover and benefit from past experience. Since the development of the computer in the mid-twentieth century, it has been discovered that the computer can perform more complex tasks than we thought, where it can discover the evidence. On the other and Klumpp (2018) noted that there are some applications that have been able to match the level of performance of experts and professionals to perform specific tasks, and these limited applications that artificial intelligence was able to do are medical diagnosis, computer search engines and its ability to recognize voice and handwriting. Lu et al. (2018) defined AI as the public domain that covers everything related to the acquisition of machines as "intelligence", in order to simulate the unique logical thinking abilities of human. Developments in AI have intensified discussions; especially as they pose a threat to mankind, both physically and economically (the idea of universal basic income has also been raised by AI, and is being tested in certain countries) (Li \& Du, 2017; Brenner, 2008). According to Bond and Gasser (2014) renowned physicist "Stephen Hawking" pointed out that the development of full-fledged artificial intelligence could pave the way for the annihilation of mankind, warning that machines could redesign themselves, as Microsoft founder and former president "Bill Gates" announced that it is better for robots to remain somewhat stupid arguing "I am in the camp of those who are concerned about supernatural intelligence". In contrast, some experts believe that artificial intelligence techniques will not pose any risks to the human race, including the professor of computer science at the University of Montreal, Canadian Joshua Pingyu, who believes that should not be concerned about smart technologies, They need many years of The evolution of the slow and progressive before it reaches the extent to which analysts fear (Helman, 2013; Rashid et al., 2014; Vieira, 2013).

\subsubsection{Expert Systems}

Expert system was defined by Turban et al. (2014) as computer programs which depend on artificial intelligence to solve all problems inside an organization within a specialty that normally requires human expert. Masterman and Masterman (2013) noted that the idea of expert systems was firstly present back in 1965 by Joshua Lederberg and Edward Feigenbaum from Stanford University in California, USA. Expert systems were produced at first in order to analyze chemical compounds but now it has incorporated reaching fields of diagnostic medicines, engineering and financial investment. On the other hand, Khalil (1993: 313) defined expert systems as "knowledge-based information systems which are expected to have human attributes in order to replicate human capacity in ethical decision making”. Ericsson et al. (2018) noted that among the most famous usages of expert systems include counseling, explain many entries, predict conclusions, justify conclusions, suggest varied options for a certain solution and orient the human expert in decision making process.

\subsubsection{Contents of Expert Systems}

Usually, expert systems are based on two main components which are knowledge base and inference engine; as for knowledge base it refers to a group of facts and postulates that are related to a certain field of interest in order to help develop a certain set of results. Inference engine is the part of expert systems which are involved with the typical tasks for expert systems like classification, diagnosis, monitoring, surveillance, design, scheduling and planning for specialized endeavors (Turban et al., 2014).

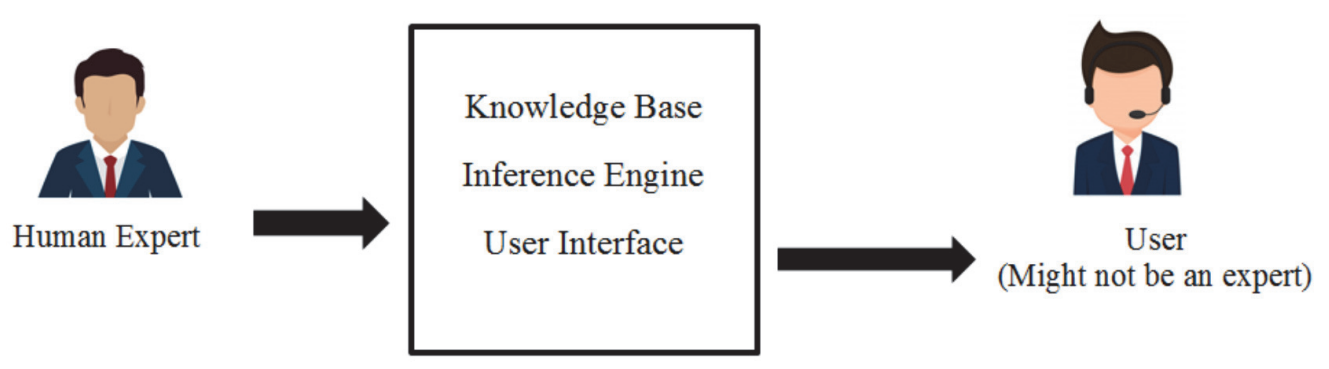

Fig. 2. Simplified Expert System

Fig. 2 explains in simple visual aid the reality of an expert system, the human experts enters all the knowledge they have regarding a certain field of interest that needs to be tackled and handled depending on a human expert; the knowledge is now saved and processed within the system, after that, and depending on suitable user interface any non-expert user can use the system to tackle certain problems within the field of interest and save time and effort. According to Khalil (1993), Hashem (2013) and Turban et al. (2014); the knowledge base within expert systems are retrieved from human experts based on observations, trials and errors in addition to interviews. This knowledge is normally presented based on the formula of "if-then" aka; production rule which means that if the condition is "true" then the next conclusion can be done of the next decision is 
valid. It is worth to mention here that knowledge base contains a massive amount of information and most probably it is combined with a lot of possibilities in case the conclusion is not valid for a certain reason. Salas et al. (2010) stated that another content of expert system is the "heuristic rules" which are retrieved from official books and sources in order to avoid risks and make the most valid conclusion there is.

\subsubsection{Characteristics of Expert Systems}

Just like any other item in our lives; expert systems enjoy massive characteristics whether they were positive or negative. Expert systems are known to have fast performance which is a positive side for the sake of saving time and effort. In addition to that, expert systems are one of the programs that are known to be user friendly due to its flexibility in the design of the user interface not to mention its credibility to be used and high responsiveness. Among the characteristics of expert system is the fact that they are connected to the organizational data base, so if the organizational is not based on a data base or it lacks such a tool in its internal processes then it would be impossible to build and depend on an expert system to activate it within an organization (Willcocks, 2013). There appeared many characteristics for expert systems other than what was mentioned above. Among these characteristics are:

\section{a. Lack of human intelligence}

It refers to the fact that all AI machines and software lack the human resilience and the ability to fit any sudden risk or situation. Expert systems might be the production of human, but it still does not have the human ability to tackle and handle any situation that requires a unique and outstanding solution as a decision making process (Scarbrough \& Corbett, 2013).

\section{b. Lack of values}

Values are not and will not be a part of AI or expert system at all. Values are varied and it may differ as according to the situation that occurs. Based on that, values are not part of expert system and data entry for values wouldn't be a smart option (Medsker, 2012).

\section{c. Lack of emotions}

This characteristic might appear as valid since expert systems are not subjected to emotions and feelings, for that part it might come up with a valid decision that is able to resolve a conflict (Marcus, 2013).

\section{d. Accidental bias}

Accidental bias can appear within expert systems only if data were manipulated. A machine cannot be bias to a certain entry on the expense of other, but if data were manipulated then there is a good chance that there would appear a certain level for bias that accidental not intentional (Marcus, 2013).

\subsubsection{Criticism and Pitfalls}

Becerra-Fernandez and Sabherwal (2014) argued that no matter how developed and sophisticated expert systems are it still can be no more than an "aid" for human experts, it cannot be considered as a substitute for the human expert at any point due to the fact that the degree of flexibility and resilience in human expert is way more valid compared to expert systems, in addition to that Khodakarami and Chan (2014) noted the concept of ethics and values which are not a part of the computerized programs and software under any circumstances. On the other hand, Krishnamoorthy and Rajeev (2018) appeared arguing that many of human qualities can be embedded within expert systems due to its ability to be formed just as according to what a human expert seeks. Zimmermann (2012) meant by that is expert systems can be managed to learn from trial and errors in addition to tackle some ethical concerns depending on deep learning and machine learning techniques. On the other hand, expert systems were criticized for their inability to be a valid substitute for the human expert on the long run as Puppe (2012) stated as it does not have the human abilities which qualifies a person to be an expert in a certain field, Willcocks (2013) also noted to one of the flaws within expert system which is that these systems are based to come up with conclusions that are connected to a certain rule without exceptions so it is not valid for all situations not to mention that since expert systems are based on human entry of information then it is in a constant need for revision and updating. Tran et al. (2016) supported the criticism pointed to expert systems arguing that such systems lacks flexibility and resilience which makes them invalid for all and every situation there is, not to mention that they lack many human abilities including the ethical orientation which is only found within humans and no other entity can have it. Hunt et al. (2012) criticized expert systems depending on their inability to give deep and profound explanations for a certain problem, its inability to verify the conclusions that it gives and its developments' costs are too expensive. 


\subsection{Expert System in Ethical Business Environment}

The idea of ethics has long been known as a virtue and quality of human race. There has not been any source of ethics other than human and that is why ethics are considered to be unique and specified in their source which is human. With the course of time, and with the ongoing developments of technological tools and apparatus which serves as a back for organizational decisions, there appeared expert systems which proved its efficiency in operating internal process of the organizational making itself a valid option to be used as a replacement of human experience (Ziarko, 2012). Leikas et al. (2019) appeared arguing with what was mentioned before. The author argued that ethics can be - at some point - embedded within artificial intelligence through the process of programing that matches the ability of different programs and systems. In taking a deeper look at this idea it can be understood as if Leikas et al. (2019) claim the ability to pass the infrastructure of ethics and values from human to machine, it means for machine to act and feel just like humans, to be able to differentiate between what wrong and what is right, and to make the right decisions no matter what circumstances were. In that Leikas et al. (2019) argued in their study that it is possible to embed some ethical concerns and values within artificial intelligence and expert systems through focusing on aligning them with the fundamental ethics and values of human nature. This can take place - as according to Leikas et al. (2019) - through deploying ethical stands, values and virtues in their fundamental basic approach within expert systems depending on an intelligence designs supported by different methodologies and processes.

\section{Material and Methods}

\subsection{Methodological Approach}

Methodological approach is the plan that a researcher designs in order to work on a research project. For that sake, a quantitative approach was adopted in order to realize the main aim of current study. Quantitative approach was defined by Eyisi (2016) as a research plan that depends on realizing the aim of study based on numeric processing of the gathered data, usually the numeric processes are utilized through SPSS and AMOS. So, researchers here employed SPSS in order to screen and process the gathered data and the numeric data which will result from SPSS will be translated into words highlighting the orientations through means and averages.

\subsection{Primary and Secondary Materials}

Primary data in current study depended on data retrieved from sample of study through the designed tool. As for secondary data it was retrieved from books, journals and articles which examined the main topic with analysis and criticism.

\subsection{Data Gathering Tool}

One of quantitative approach tools is a questionnaire. This tool consists of statements that are subjected to different levels of understanding, thes levels were realized in a scale called Likert scale. In the case of current study, Likert 5 scale was adopted (strongly agree, agree, neutral, disagree, and strongly disagree). Statements of questionnaire were developed depending on studies related to the main focus of study and from problem statements was derived.

\subsection{Population and Sample}

Researchers have chosen the construction sector in Jordan to represent the population of study. Referring to Amman chamber of commerce; it was found that Jordanian construction sector consisted of 12 sub-sectors. Sample of 200 individuals were chosen to represent sample of study who were general manager, deputy managers and project managers within the aforementioned 12 sub-sectors, after application process, total of (132) individuals responded to the questionnaire properly which makes the response ration statically acceptable (66)\%.

\subsection{Data Screening and Statistical Processing}

$21^{\text {st }}$ Ed. Of SPSS was used to screen and process gathered data. The following tests were applied:

- Descriptive statistics

- Multiple regression

- Simple regression

\subsection{Reliability Test}

A reliability test was carried out using Cronbach's' alpha, the result showed a value of (0.848) for the all items as well as alpha for each variable is greater than accepted percent 0.60 , which is a reasonable value indicating the tool consistency that enhanced its use for the study. 


\section{Results}

In order to be aware of responses orientation of study sample, demographics were calculated according to age, gender, job and education. It was revealed that majority of sample were males forming $57.6 \%$ of the total sample whose age ranged between 31-36 years old forming 39.4\% of the sample and who hold MA holders forming $73.5 \%$ working as officers forming $25.8 \%$ of the total sample. The responses highlighted the high awareness of construction sector in Jordan of expert systems and its varied uses within the sector for decision making processes.

Table 1

Descriptive Statistics

\begin{tabular}{|c|c|c|c|c|c|}
\hline & $\mathrm{N}$ & $\min$ & $\max$ & Mean & Std. Dev. \\
\hline \multicolumn{6}{|l|}{ Lack of Human Intelligence } \\
\hline No matter how smart expert systems are they still lack the human motivator & 132 & 1 & 5 & 1.80 & .886 \\
\hline Expert system is mostly based on speed and accuracy not to replace human factor & 132 & 1 & 5 & 1.87 & .833 \\
\hline Logical processes are made by expert systems not emotional and ethical & 132 & 1 & 4 & 1.77 & .747 \\
\hline The philosophy of ethics can't be digested by expert systems & 132 & 1 & 5 & 1.77 & .790 \\
\hline $\begin{array}{l}\text { The lack of "human" intelligence can cause some ethical concerns when using these systems in } \\
\text { a decision making capacity. }\end{array}$ & 132 & 1 & 4 & 1.78 & .745 \\
\hline \multicolumn{6}{|l|}{ Lack of Emotions } \\
\hline $\begin{array}{l}\text { The lack of emotions can't cause ethical concerns when using these systems in a decision mak- } \\
\text { ing capacity. }\end{array}$ & 132 & 1 & 5 & 1.92 & .896 \\
\hline There can be place for emotions within technological apparatus in the coming future & 132 & 1 & 4 & 1.80 & .878 \\
\hline $\begin{array}{l}\text { Expert systems are made to take logical decisions but with development they can make emo- } \\
\text { tional decisions }\end{array}$ & 132 & 1 & 5 & 1.87 & .814 \\
\hline The idea of emotions is a part of expert systems & 132 & 1 & 4 & 1.80 & .776 \\
\hline Artificial decision making can be gathered with emotions & 132 & 1 & 5 & 2.15 & .992 \\
\hline \multicolumn{6}{|l|}{ Accidental Bias } \\
\hline Expert systems' intelligence and in- biasedness can't problematic when making decisions. & 132 & 1 & 5 & 2.11 & .897 \\
\hline Biasness can't be an issue with expert system as data can't be manipulated & 132 & 1 & 5 & 2.14 & .931 \\
\hline $\begin{array}{l}\text { Expert systems are normally not prejudice against any specific client when its operating in an } \\
\text { ethical climate }\end{array}$ & 132 & 1 & 5 & 2.05 & .999 \\
\hline $\begin{array}{l}\text { There is no existence of intentional or accidental bias; this can't cause ethical concerns when us- } \\
\text { ing these systems in a decision making capacity. }\end{array}$ & 132 & 1 & 5 & 2.17 & .887 \\
\hline any biases held by the knowledge engineer can't influence the way the decisions are made & 132 & 1 & 4 & 1.92 & .742 \\
\hline \multicolumn{6}{|l|}{ Lack of value } \\
\hline intelligent machines will - in the future - embody values, assumptions, and purposes & 132 & 1 & 4 & 1.94 & .718 \\
\hline Values are a part of decision making process in expert systems & 132 & 1 & 4 & 2.10 & .760 \\
\hline Organizations are already satisfied with the level of expert systems & 132 & 1 & 4 & 2.02 & .819 \\
\hline $\begin{array}{l}\text { The tacit assumptions and values of well-intentioned systems designers couldn't cause deci- } \\
\text { sion makers to drift in a direction they might not have taken by choice. }\end{array}$ & 132 & 1 & 4 & 2.03 & .837 \\
\hline $\begin{array}{l}\text { The lack of values can't cause ethical concerns when using these systems in a decision making } \\
\text { capacity. }\end{array}$ & 132 & 1 & 5 & 2.23 & .915 \\
\hline \multicolumn{6}{|l|}{ Ethics-Based Decision Making Process } \\
\hline Ethics are a part of the human nature & 132 & 2 & 5 & 3.99 & .746 \\
\hline Ethics can be embedded in an operating system & 132 & 2 & 5 & 4.12 & .752 \\
\hline Ethics can be subjected to a certain formula & 132 & 2 & 5 & 4.12 & .742 \\
\hline Ethics can hold bias, lack of value, emotions or human intelligence & 132 & 2 & 5 & 4.39 & .588 \\
\hline $\begin{array}{l}\text { Ethics are based on operating human skills and abilities it can also be involved within expert } \\
\text { systems }\end{array}$ & 132 & 2 & 5 & 4.22 & .745 \\
\hline
\end{tabular}

As it can be seen from Table 1, it was highlighted through analysis that there was a vivid positive attitude from participants towards questions (21-25) as their means were higher than mean of the scale (3), on the other hand, the remaining questions confirmed a negative attitudes since there mean was lower than mean of scale (3).

Table 2

Descriptive Statistics of Variables

\begin{tabular}{lccccc}
\hline & $\mathrm{N}$ & Minimum & Maximum & Mean & Std. Deviation \\
\hline Lack of human intelligence & 132 & 1.00 & 4.00 & 1.7985 & .59025 \\
Lack of emotions & 132 & 1.00 & 4.40 & 1.9106 & .63742 \\
Accidental bias & 132 & 1.00 & 4.40 & 2.0788 & .70927 \\
Lack of values & 132 & 1.00 & 3.80 & 2.0636 & .64076 \\
Ethics-Based Decision Making Process & 132 & 2.80 & 5.00 & 4.1682 & .50393 \\
\hline Valid N (listwise) & 132 & & & \\
\hline
\end{tabular}

Examining the results of Table 2, (Ethics-Based Decision Making Process) scored a positive attitude confirming the existence and importance of ethics-based decision making process as the mean of the variable scored higher than (3), on the contrary, study variables representing areas of interest in expert systems scored lower than mean of scale indicating that these variables were negatively answered (Lack of human intelligence, Accidental bias, Lack of emotions and Lack of values). This result 
indicated that the taken characteristics of expert system proved to be negatively influential on decision making process within such systems.

\subsection{Hypotheses Testing}

Main hypothesis: The effect of characteristics of the expert system on ethics-based decision making process

The results of the survey have indicated that Adjusted R-Square is equal to 0.44, which means the independent variables can explained approximately $44 \%$ of the changes of the dependent variable. Moreover, the result of ANOVA test has yielded a F-value of 26.779 (0.000), which means there is a linear relationship between independent variables and dependent variable. Table 3 shows the results of the regression analysis.

Table 3

The summary of the results of regression analysis

\begin{tabular}{|c|c|c|c|c|c|c|}
\hline & \multirow[t]{2}{*}{ Model } & \multicolumn{2}{|c|}{ Unstandardized Coefficients } & \multirow{2}{*}{$\frac{\text { Standardized Coefficients }}{\text { Beta }}$} & \multirow[t]{2}{*}{$\mathrm{t}$} & \multirow[t]{2}{*}{ Sig. } \\
\hline & & $\mathrm{B}$ & Std. Error & & & \\
\hline \multirow[t]{5}{*}{1} & (Constant) & 5.341 & .127 & & 42.216 & .000 \\
\hline & Intelligence & .003 & .076 & .004 & .045 & .964 \\
\hline & Emotions & -.265 & .096 & -.336 & -2.776 & .006 \\
\hline & Accidental & -.076 & .085 & -.106 & -.894 & .373 \\
\hline & Value & -.249 & .074 & -.317 & -3.365 & .001 \\
\hline
\end{tabular}

The results of Table 3 show that that Emotion and Value have meaningful negative impacts on decision making process when the level of significance is one percent and other variables; namely Intelligence and Accidental variables do not provide meaningful impacts on decision making process when the level of significance is five or even ten percent.

\subsubsection{First sub-hypothesis: The effect of lack of human intelligence on ethics-based decision making}

The results of the survey have indicated that Adjusted R-Square is equal to 0.171, which means the independent variable can explained approximately $17 \%$ of the changes of the dependent variable. Moreover, the result of ANOVA test has provided a F-value of $28.014(0.000)$, which means there is a linear relationship between independent variable and dependent variable. Table 4 shows the results of the regression analysis.

\section{Table 4}

The summary of the results of regression analysis between lack of human intelligence and ethics-based decision making

\begin{tabular}{|c|c|c|c|c|c|c|}
\hline & \multirow[t]{2}{*}{ Model } & \multicolumn{2}{|c|}{ Unstandardized Coefficients } & \multirow{2}{*}{$\frac{\text { Standardized Coefficients }}{\text { Beta }}$} & \multirow[t]{2}{*}{$\mathrm{t}$} & \multirow[t]{2}{*}{ Sig. } \\
\hline \multirow{3}{*}{1} & & $\mathrm{~B}$ & Std. Error & & & \\
\hline & (Constant) & 4.815 & .129 & & 37.465 & .000 \\
\hline & intelligence & -.359 & .068 & -.421 & -5.293 & .000 \\
\hline
\end{tabular}

The results of Table 4 have suggested that intelligence statistically has a negative influence on ethics-based decision making. Note that the effect of this variable is not significant when this variable is combined with other variables as shown in Table 3. The reason is mainly because there were some correlations between independent variable.

\subsubsection{Second sub-hypothesis: The effect of Emotions on ethics-based decision making process}

The results of the survey have indicated that Adjusted R-Square is equal to 0.372, which means the independent variable can explained approximately $37 \%$ of the changes of the dependent variable. Moreover, the result of ANOVA test has provided a F-value of $78.463(0.000)$, which means there is a linear relationship between independent variable and dependent variable. Table 5 demonstrates the results of the regression analysis.

Table 5

The summary of the results of regression analysis between lack of emotions and ethics-based decision making

\begin{tabular}{ccccccc}
\hline \multirow{2}{*}{ Model } & \multicolumn{2}{c}{ Unstandardized Coefficients } & Standardized Coefficients & \multirow{2}{*}{ S } & \\
\cline { 2 - 6 } 1 & & $\mathrm{~B}$ & Std. Error & Beta & \\
\cline { 2 - 6 } & (Constant) & 5.095 & .110 & & 46.215 & .000 \\
& Emotions & -.485 & .055 & -.614 & -8.858 & .000 \\
\hline
\end{tabular}

The results have indicated that Emotions play essential role on ethics-based decision making when the level of significance is one percent.

\subsubsection{Third sub-hypothesis: The effect of accidental bias on ethics-based decision making process}


The results of the survey have indicated that Adjusted R-Square is equal to 0.347, which means the independent variable can explained approximately $35 \%$ of the changes of the dependent variable. Moreover, the result of ANOVA test has provided a F-value of 70.695 (0.000), which means there is a linear relationship between independent variable and dependent variable. Table 6 demonstrates the results of the regression analysis.

Table 6

The summary of the results of regression analysis between Accidental and ethics-based decision making

\begin{tabular}{|c|c|c|c|c|c|c|}
\hline & \multirow[t]{2}{*}{ Model } & \multicolumn{2}{|c|}{ Unstandardized Coefficients } & \multirow{2}{*}{$\begin{array}{c}\text { Standardized Coefficients } \\
\text { Beta }\end{array}$} & \multirow[t]{2}{*}{$\mathrm{t}$} & \multirow[t]{2}{*}{ Sig. } \\
\hline & & $\mathrm{B}$ & Std. Error & & & \\
\hline \multirow[t]{2}{*}{1} & (Constant) & 5.045 & .110 & & 45.814 & .000 \\
\hline & Accidental & -.422 & .050 & -.594 & -8.408 & .000 \\
\hline
\end{tabular}

The results have indicated that Accidental plays an essential negative role on ethics-based decision making when the level of significance is one percent.

\subsubsection{Fourth sub-hypothesis: The effect of value on ethics-based decision making process}

The results of the survey have indicated that Adjusted R-Square is equal to 0.355, which means the independent variable can explained approximately $36 \%$ of the changes of the dependent variable. Moreover, the result of ANOVA test has provided a F-value of $73.062(0.000)$, which means there is a linear relationship between independent variable and dependent variable. Table 7 presents the results of the regression analysis.

Table 7

The summary of the results of regression analysis between lack of values and ethics-based decision making

\begin{tabular}{|c|c|c|c|c|c|c|}
\hline \multirow{2}{*}{\multicolumn{2}{|c|}{ Model }} & \multicolumn{2}{|c|}{ Unstandardized Coefficients } & \multirow{2}{*}{$\frac{\text { Standardized Coefficients }}{\text { Beta }}$} & \multirow[t]{2}{*}{$\mathrm{t}$} & \multirow[t]{2}{*}{ Sig. } \\
\hline & & $\mathrm{B}$ & Std. Error & & & \\
\hline \multirow[t]{2}{*}{1} & (Constant) & 5.142 & .119 & & 43.129 & .000 \\
\hline & Value & -.472 & .055 & -.600 & -8.548 & .000 \\
\hline
\end{tabular}

The results have indicated that Value plays an essential negative role on ethics-based decision making when the level of significance is one percent. Note that the effect of this variable is not significant when this variable is combined with other variables as shown in Table 3. The reason is mainly because there were some correlations between independent variable.

\section{Discussion}

As it appeared from study analysis, the chosen set of expert systems were found to be of negative influence of some expert system characteristics on the ethical stands of organizational decision making process. It is widely known that in an environment where humans are integral part of it there is no place for mono-situation. Each and every situation is unique and different with the varied elements that contributed into creating such a situation. Results of study indicated that the chosen set of expert systems characteristics proved its negative influence on the decision making process of the organizational making no space for ethical stream. With a $\mathrm{R}$ value of 0.676 it was revealed that the chosen characteristics of expert system can influence ethics-based decision making process. Among variables, the results of study indicated that lack of value was the most influential factor of all referring to the fact that the lack of values within expert systems can hinder the ethical based decision making process making ethics within organization hard to reach which was also supported by Bostrom and Yudkowsky (2014). The idea is that human values are exclusive to human, which means that there are many values each and every one of them suit a certain situation and criteria; entering all possible values would appear as a form of mission impossible as it is impossible to be aware of value there is. In addition, entering values that are mostly common might not be considered as a valid solution given that not every one of them may suit the situation under examination as Rossi (2019) also saw in his study. Following the influence of lack of values there appeared that lack of human intelligence was influential on the ethical decision making process within an organization. In that sense, regardless of the fact that a human is the only source for developing expert systems they still lack the reality of human intelligence and its ability to be resilient and flexible with any sudden or possible situation that needs to be resolved and tackled immediately. As for expert systems, they are only restricted to the data entry which was done by human source and this makes them limited in their intelligence level as agreed on by Leslie (2019). Accidental bias also appeared to be influential on the level of ethical decision making. This cannot appear on purpose that is why researchers referred to it as accidental not intentional. An expert system cannot take any intentional decision due to its inability to be bias to any group or side. The bias might appear as a result of data entry malfunction which might be manipulated for the benefit of a certain side on the expense of another which was also agreed on by Bryson and Winfield (2017).

Through analysis, it appeared that one of the variables taken into consideration played a positive role in increasing the efficiency of expert systems activities, lack of emotions was seen to be positive in influence referring to the concept of emotionless based decision making process as positive for the well-fare of the organization and the degree of health that these decisions might have. Results of study seemed to meet with many scholars who argued of the fact that an expert system would not - at 
any level - support and back up ethical trials within an organization including Raho et al. (1994); Khalil (1994); Dillard and Yuthas (2001) and Hashem (2013).

\section{Conclusion}

Human abilities are varied and exceptional. AI machines and technology in general were built and developed not to replace the human intelligence but mostly to play a role in supporting the human activities and speed them up by saving time and efforts. The idea of expert systems is made in order to make experienced and well-informed decision in a certain field of interest. Just like any other technologies it has faced much criticism as it lacks many aspects that qualify them to replace the human expertise and do human work as a whole. No matter how technology was developed, the idea of ethics and values are still one of the human virtues and there is no machine that could have the ability to outperform a human being in differentiating between wrong and right; not until a human gives it the access to that point. This study confirmed that some of expert systems characteristic opposes and disagrees with the basic meaning of ethics. Any machine that is based on data entry can be easily manipulated leading to bad decisions that would not be for the well-fare of the organization. For that sake, researchers of current study recommended:

- Managerial action should not be based on machines and technology, the idea of higher management is to take wellinformed decisions that are sourced from a human. So, the managerial efforts must be apparent even if there were a high reliance on expert systems.

- Continuous development and monitoring of expert systems are important. Usually these systems are developed through a human factor. Ethical surveillance should be the tasks of the human not the system itself.

\section{References}

Becerra-Fernandez, I., \& Sabherwal, R. (2014). Knowledge management: Systems and processes. Routledge.

Bond, A. H., \& Gasser, L. (Eds.). (2014). Readings in distributed artificial intelligence. Morgan Kaufmann.

Bostrom, N., \& Yudkowsky, E. (2014). The ethics of artificial intelligence. The Cambridge handbook of artificial intelligence, 316, 334.

Brenner, B. (2008). A computerized business ethics expert system: A new approach to improving the ethical quality of business decision-making. Journal of Systemics, Cybernetics and Informatics, 3(3), 86-90.

Bryson, J., \& Winfield, A. (2017). Standardizing ethical design for artificial intelligence and autonomous systems. Computer, 50(5), 116-119.

Dillard, J. F., \& Yuthas, K. (2001). A responsibility ethics for audit expert systems. Journal of Business Ethics, 30(4), 337359.

Dirican, C. (2015). The impacts of robotics, artificial intelligence on business and economics. Procedia-Social and Behavioral Sciences, 195, 564-573.

Ericsson, K. A., Hoffman, R. R., Kozbelt, A., \& Williams, A. M. (Eds.). (2018). The Cambridge handbook of expertise and expert performance. Cambridge University Press.

Eyisi, D. (2016). The usefulness of qualitative and quantitative approaches and methods in researching problem-solving ability in science education curriculum. Journal of Education and Practice, 7(15), 91-100.

Hashem, T. (2013). Marketing Manager's Perception of advantages and disadvantages of expert systems in the Jordanian Commercial banks. Research Gate

Helman, D. H. (Ed.). (2013). Analogical reasoning: Perspectives of artificial intelligence, cognitive science, and philosophy (Vol. 197). Springer Science \& Business Media.

Hunt, K. J., Irwin, G. R., \& Warwick, K. (Eds.). (2012). Neural network engineering in dynamic control systems. Springer Science \& Business Media.

Khalil, O. E. (1993). Artificial decision-making and artificial ethics: A management concern. Journal of Business Ethics, 12(4), 313-321.

Khodakarami, F., \& Chan, Y. E. (2014). Exploring the role of customer relationship management (CRM) systems in customer knowledge creation. Information \& Management, 51(1), 27-42.

Klumpp, M. (2018). Automation and artificial intelligence in business logistics systems: human reactions and collaboration requirements. International Journal of Logistics Research and Applications, 21(3), 224-242.

Krishnamoorthy, C. S., \& Rajeev, S. (2018). Artificial intelligence and expert systems for engineers. CRC press.

Kwakye, O., Yusheng, K., Ayamba, E. C., \& Osei, A. A. (2018). Influence of ethical behavior on Corporate Governance of firm's performance in Ghana. International Journal of Scientific Research and Management, 6(06).

Leikas, J., Koivisto, R., \& Gotcheva, N. (2019). Ethical Framework for Designing Autonomous Intelligent Systems. Journal of Open Innovation: Technology, Market, and Complexity, 5(1), 18.

Leslie, D. (2019). Understanding artificial intelligence ethics and safety. arXiv preprint arXiv:1906.05684.

Li, D., \& Du, Y. (2017). Artificial intelligence with uncertainty. CRC press.

Lu, H., Li, Y., Chen, M., Kim, H., \&Serikawa, S. (2018). Brain intelligence: go beyond artificial intelligence. Mobile Networks and Applications, 23(2), 368-375. 
Marcus, S. (Ed.). (2013). Automating knowledge acquisition for expert systems (Vol. 57). Springer Science \& Business Media. Masterman, J. W., \& Masterman, J. (2013). An introduction to building procurement systems. Routledge.

Medsker, L. R. (2012). Hybrid neural network and expert systems. Springer Science \& Business Media.

Puppe, F. (2012). Systematic introduction to expert systems: Knowledge representations and problem-solving methods. Springer Science \& Business Media.

Raho, L. E., Belohlav, J. A., \& Drehmer, D. R. (1994). Expert systems in organizations: Legal and ethical considerations. Information and Communications Technology Law, 3(1), 47-57.

Ransbotham, S., Kiron, D., Gerbert, P., \& Reeves, M. (2017). Reshaping business with artificial intelligence: Closing the gap between ambition and action. MIT Sloan Management Review, 59(1).

Rashid, N., Fizzah, S., \& Alvi, M. (2014). Impact of business ethics on organizational development in telecom sector of Pakistan. Journal of Applied Environment and Biological Sciences, 4(9s), 45-51

Rossi, F. (2019). Building trust in artificial intelligence. Journal of International Affairs, 72(1), 127-134.

Salas, E., Rosen, M. A., \& DiazGranados, D. (2010). Expertise-based intuition and decision making in organizations. Journal of Management, 36(4), 941-973.

Scarbrough, H., \& Corbett, J. M. (2013). Technology and Organization (RLE: Organizations): Power, Meaning and Deisgn. Routledge.

Skilton, M., \& Hovsepian, F. (2017). The 4th Industrial Revolution: Responding to the Impact of Artificial Intelligence on Business. Springer.

Tran, D., Kucukelbir, A., Dieng, A. B., Rudolph, M., Liang, D., \&Blei, D. M. (2016). Edward: A library for probabilistic modeling, inference, and criticism. arXiv preprint arXiv: 1610.09787.

Turban, E., Sharda, R., \& Delen, D. (2010). Decision support and business intelligence systems (required). Google Scholar.

Vieira, M. E. R. (2013). The effects of ethical behavior on the profitability of firms: a study of the Portuguese construction industry (Doctoral dissertation).

Wigan, M. R. (1987). Legal and ethical issues in expert systems used in planning. Environment and planning B: Planning and design, 14(3), 305-321.

Willcocks, L. (2013). Information management: the evaluation of information systems investments. Springer.

Wu, D. D., Chen, S. H., \& Olson, D. L. (2014). Business intelligence in risk management: Some recent progresses. Information Sciences, 256, 1-7.

Ziarko, W. P. (Ed.). (2012). Rough Sets, Fuzzy Sets and Knowledge Discovery: Proceedings of the International Workshop on Rough Sets and Knowledge Discovery (RSKD'93), Banff, Alberta, Canada, 12-15 October 1993. Springer Science \& Business Media.

Zimmermann, H. J. (2012). Fuzzy sets, decision making, and expert systems (Vol. 10). Springer Science \& Business Media.

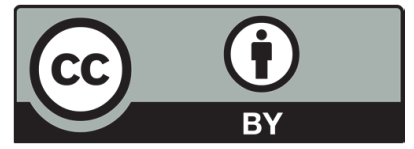

(C) 2020 by the authors; licensee Growing Science, Canada. This is an open access article distributed under the terms and conditions of the Creative Commons Attribution (CC-BY) license (http://creativecommons.org/licenses/by/4.0/). 